American Journal of Pharmaceutical Education 2020; 84 (9) Article 7949.

\title{
COMMENTARY
}

\section{Does Social Desirability Influence Preceptors' Completion of Student Experiential Evaluations?}

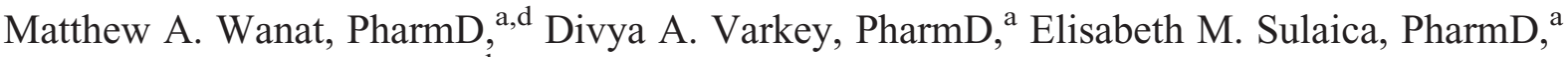 \\ Kelly A. Thornton, PharmD, ${ }^{b}$ J. Douglas Thornton, PharmD, $\mathrm{PhD}^{\mathrm{c}}$ \\ ${ }^{a}$ University of Houston, College of Pharmacy, Houston, Texas \\ ${ }^{\mathrm{b}}$ Memorial-Herman Hospital, Department of Pharmacy, Houston, Texas \\ ${ }^{\mathrm{c}}$ University of Houston, College of Pharmacy, Houston, Texas \\ ${ }^{\mathrm{d}}$ Editorial Board Member, American Journal of Pharmaceutical Education, Arlington, Virginia \\ Submitted December 6, 2019; accepted March 22, 2020; published September 2020.
}

Many variables influence a preceptor's experiential evaluation of a pharmacy learner. However, the impact of social desirability bias, or the measure of an individual's need for social approval, and its impact on the truthfulness of an evaluation is not well understood. Social desirability may present a barrier to students receiving accurate and truthful evaluations. Differences in the effect of social desirability may be seen between full-time faculty and non-faculty preceptors. Colleges of pharmacy should work to support preceptors by providing professional development, standardizing evaluation processes, and ensuring two-way communication. Additionally, a social desirability measure could be used for each preceptor and used by the experiential team to identify preceptors potentially in need of additional development. Future studies should evaluate the effect of social desirability on how preceptors complete evaluations, and propose methods to mitigate this form of bias in the evaluation process.

Keywords: social desirability, preceptor development, evaluations, experiential education

\section{INTRODUCTION}

Frequent evaluations are administered to pharmacy learners during the experiential education portion of the Doctor of Pharmacy (PharmD) curriculum. Evaluations, either formative or summative in nature, may be based on performance from introductory pharmacy practice experiences (IPPEs), advanced pharmacy practice experiences (APPEs), interprofessional experiences (IPEs), and cocurricular activities. Many cognitive and noncognitive variables affect summative experiential evaluations, such as the student's performance, clinical knowledge base, communication skills, and empathy, as well as interactions between the learner, preceptor, and the medical team. ${ }^{1}$ However, a less well understood factor is the concept of social desirability and its potential effect on how pharmacy learner evaluations are completed. ${ }^{2}$

Social desirability was first introduced as a measure of an individual's need for social approval, and has been described as a personality characteristic that can affect the validity of survey responses. ${ }^{2,3}$ Researchers have

Corresponding Author: Matthew Wanat, Department of Pharmacy Practice and Translational Research, University of Houston College of Pharmacy, 4849 Calhoun Rd., Houston, TX. Tel: 832-842-8367. Email: MAWanat@uh.edu previously described that social desirability usually occurs in a three construct model: impression management, self-deceptive enhancement, and self-deceptive denial. ${ }^{4}$ Impression management is the process by which people attempt to control how they are perceived by others, while self-deception enhancement and denial use false impressions to convince others of their truths. ${ }^{3-5}$ Operationally, it is the tendency of research subjects, or in this scenario preceptors, to provide socially desirable responses instead of responses that reflect their true feelings. This desire to be socially accepted may play a role in a preceptor's evaluations of pharmacy students' experiential learning.

Accreditation Council for Pharmacy Education (ACPE) Standard 20 requires colleges of pharmacy to have a sufficient number of preceptors to evaluate students in the experiential setting. ${ }^{1}$ These preceptors can be full-time faculty members or external practitioners who are primarily employed by an institution outside the college. Benefits provided to non-full-time faculty preceptors may include adjunct appointment status, electronic library access, lecture or teaching opportunities, or other tangible benefits not provided by their primary employer. Non-full-time faculty preceptors may feel their ability to 


\section{American Journal of Pharmaceutical Education 2020; 84 (9) Article 7949.}

remain a preceptor for a particular school and to continue receiving these benefits may be tied to student evaluations of their precepting. Thus, social desirability bias could lead preceptors to inflate their evaluations of student performance, which might result in the preceptor being viewed more positively by students as well as college faculty members and administrators, and may also prevent negative feedback from corresponding learners. This form of bias may also be present among faculty preceptors, although the specific positive attributes and effect on their career may be different from those for non-faculty preceptors. Of note, social desirability bias may also occur conversely, where the pharmacy learner provides an untruthful evaluation of their preceptor for many of the same reasons provided above.

The effect of social desirability on student evaluations has not been well described in health professions education. To date, no studies have directly assessed the role of social desirability on pharmacy preceptor ability to complete evaluations that are accurate and honest. The goal of this commentary is to discuss barriers that affect truth in completing experiential evaluations, including social desirability, to compare and contrast the potential effect of social desirability in evaluations between faculty preceptors and non-faculty preceptors, and to provide recommendations to complete experiential evaluations with this bias being limited.

\section{Barriers in Completing Truthful Experiential Eval- uations Among Health Care Practitioners}

Though constructive evaluations are crucial in the development of a pharmacy learner, often social barriers can affect how "honest" evaluations are. One major concern is that providing feedback that could be viewed by the learner as negative may adversely affect the preceptor-student relationship. ${ }^{6}$ A 2012 study from the University of Pennsylvania included 44 internal medicine faculty members from 16 residency programs who watched live scenarios of encounters between medical residents and standardized patients and then provided feedback to the residents. ${ }^{7}$ The study found that the faculty members' perceived effectiveness in giving feedback, the pressure they felt to deliver both positive and negative information, and the preexisting relationship they had with the resident all impacted the feedback process. Feedback given was broken down into two styles: elaborative feedback, which involved two-way communication, and allowed the resident to respond and show understanding, or directive feedback, where the preceptor just listed feedback to the resident without allowing an opportunity for discussion, or for the resident to confirm or deny certain points. The results from this study emphasized that many variables impact the effectiveness and delivery of feedback given by preceptors.

Another concern to consider when providing a student with truthful feedback is that the student may not be able to effectively process constructive feedback or know how to incorporate the suggested changes into their performance. In a qualitative study in which 64 nursing preceptors were interviewed, respondents expressed having difficulty providing an accurate critique of nursing students. The nursing preceptors reported that students often lost confidence when they were given critical feedback. ${ }^{8}$ The individual personality traits of both the preceptor and student can also impact the comfort level of the preceptor in providing a constructive evaluation. This can ultimately influence the feedback included in a student's evaluation, ie, whether the preceptor provides or avoid providing constructive feedback. ${ }^{9}$ The inconsistency in the type of feedback preceptors provide may have a heightened negative impact on pharmacy education as more pharmacy students seek postgraduate training as the pharmacy job market becomes more competitive. Summative preceptor evaluations are not provided to residency programs as part of the application process, but the effect of the evaluations is reflected in the student's final rotation grade.

\section{Differences in Social Desirability Between Faculty and Non-faculty Preceptors}

The effect of social desirability bias is likely to be different between full-time faculty preceptors and nonfaculty preceptors. While many barriers affecting honesty in evaluations are similar between faculty and non-faculty preceptors, the driving force is likely different. As a primary function of an academic role, faculty preceptors have the opportunity to interact with students in a variety of settings and are more visible to the students over a longer period of time. These consistent and routine interactions, from classroom settings to professional organizations, allow faculty preceptors to develop a working relationship with students over time. Additionally, faculty preceptors are able to watch students grow personally and professionally through each year of the curriculum. These opportunities to work with and provide feedback to students on a routine basis give faculty preceptors an increased level of comfort with providing critical feedback to them in a constructive manner.

Student evaluations of preceptors may have a different career impact on full-time faculty preceptors than on non-faculty preceptors. Student evaluations are commonly used in the academic setting as an assessment variable for annual performance evaluations, awards, promotion, and other mechanisms that correlate with 


\section{American Journal of Pharmaceutical Education 2020; 84 (9) Article 7949.}

success as a faculty member. In comparison, student evaluations may not be as influential to the career advancement of non-faculty preceptors. Most non-faculty preceptors are not required to precept students as a mandatory function of their job. Student evaluations of non-faculty preceptors may be used by the preceptor's supervisor as part of their annual performance review, or by the school to approve monetary compensation, like funding for travel to a professional meeting, or in making decisions regarding preceptor awards. As non-faculty preceptor evaluations may not be a large component of their annual evaluation, they may be able to provide more honest feedback to students. As student evaluations of full-time faculty preceptors are a critical component of their overall faculty evaluation, they may feel pressure to provide desirable responses on students' experiential evaluations that may not be reflective of the student's actual performance. Several studies have shown that higher grades from preceptors corresponded with more positive preceptor evaluations from students. ${ }^{10-13}$ This concept is an ongoing debate with regard to its validity and how evaluations should be used in academic settings across health professions. ${ }^{14}$

\section{Empowering Preceptors in Completing Experiential Evaluations}

Non-faculty preceptors and the practice sites where they work are becoming increasingly scarce. Texas is among a growing number of states that require pharmacists to obtain continuing education to be eligible to precept pharmacy students. This is an excellent opportunity for schools of pharmacy to work with their pool of current and potential preceptors who are in need of earning required continuing education credits. A study from the University of California-San Francisco School of Pharmacy surveyed volunteer preceptors regarding various aspects of precepting. Of the 236 respondents, $73.5 \%$ desired more formal preceptor training. ${ }^{15}$ These professional development opportunities can provide preceptors a venue in which to discuss evaluation of students with their academic and professional colleagues. Live continuing education events provide preceptors the opportunity to discuss how to grade certain behaviors or inactions from students completing practice experiences as well as how to avoid social desirability bias.

Standardizing evaluation systems and preceptor development would aid in empowering preceptors to hold students accountable for their work and professional behavior while completing practice experiences. Practice sites, particularly those in large urban centers, are not school-specific and precept students from multiple colleges of pharmacy. Inevitably, precepting students from more than one institution results in a wide range of evaluation requests from the corresponding schools of pharmacy. For example, many schools use a Likert scale to evaluate different aspects of student performance, but how the response scales are operationalized to measure performance can differ widely. All online grading platforms should allow preceptors to provide written feedback in addition to Likert scale responses so they can provide specific examples that support the scores provided. Requiring documentation of specific examples of performance or behavior when scoring a student may help to mitigate social desirability bias.

Communication between the experiential team and preceptors is critical to receiving timely and actionable feedback for both the schools and students. Early and frequent communication between an experiential office and preceptors will improve preceptor confidence in troubleshooting student issues, and provide strategies to improve student performance. The college's online evaluation portals must be kept up to date with contact information for the support liaison (eg, experiential coordinator) well in advance of the start of the practice experience. The preceptor manual or college specific preceptor guide, and online grading platform should include clear and concise information regarding student expectations for the specific practice experience and the criteria on which the students will be evaluated at the midpoint and end of the rotation. Communication with the experiential education office will help to establish a relationship with preceptors. This can help to improve preceptor confidence in handling student issues and mitigate social desirability bias by appropriately documenting evaluations. As communication is a bidirectional flow of information, schools should seek feedback from preceptors. Schools should send out a preceptor survey after final evaluations are submitted so preceptors can provide feedback regarding the evaluation process. Each practice experience site will have its own implementation challenges where the standard evaluation will need to be adapted to the specific professional experience.

Finally, the experiential team can use an instrument to measure social desirability for each preceptor to identify preceptors potentially in need of additional development. ${ }^{16-18}$ The Marlow-Crowne Social Desirability Scale (MCSDS) is the oldest and most frequently used scale, but a major limitation is that the scale items are dated and do not reflect the current social culture. ${ }^{16}$ The Social Desirability Scale-17 (SDS-17), a more contemporary measure of social desirability, may be used. The SDS-17 has shown a positive correlation with impression management, one of the main characteristics of social desirability, but no correlation was seen with self-deception 


\section{American Journal of Pharmaceutical Education 2020; 84 (9) Article 7949.}

characteristics. ${ }^{18}$ The SDS-17 was less influenced by the age of respondents compared to other scales of social desirability, potentially making it better suited for use across the broader age groups of preceptors. However, because of when these scales were created, they do not take into account the influence of social media on social desirability, acceptance, and communication. Future research using social desirability scales such as the SDS-17 should be conducted in pharmacy faculty and preceptors.

\section{CONCLUSION}

The impact of social desirability on experiential evaluations may be enhanced because of the intense time commitment required and close relationship formed between the preceptor and pharmacy student during the experiential learning experience. Pharmacy schools should work with their preceptors to minimize social barriers to accurately completing experiential evaluations, provide professional development and support to preceptors to empower them to complete accurate evaluations and have potentially difficult conversations with students. For students, pharmacy schools should discuss the importance of professional experiences and continue to emphasize the need for professionalism in these settings. Directions for future studies include analyzing the effect of social desirability on preceptor evaluation accuracy and identifying methods to mitigate this form of bias in the evaluation process.

\section{REFERENCES}

1. Accreditation Council for Pharmacy Education. Accreditation standards and key elements for the professional program in pharmacy leading to the doctor of pharmacy degree, 2016. https://www.acpeaccredit.org/pdf/Standards2016FINAL.pdf. Accessed August 1, 2020.

2. Paulhus DL. Socially desirable responding: the evolution of a construct. In: Braun H, Jackson DN, Wiley DE (Eds). The Role of Contructs in Psychological and Educational Measurement. Mahwah NJ: Erlbaum. 2002:49-69.
3. Krumpal I. Determinants of social desirability bias in sensitive surveys: a literature review. Qual Quant. 2013;47:2025-2047. 4. Paulhus DL, Reid DB. Enhancement and denial in social desirability responding. Journal of Personality and Social Psychology. 1991;60:307-317.

5. Otter Z, Egan V. The evolutionalry role of self-deceptive enhancement as a protective factor against antisocial cognitions. Personality and Individual Differences. 2007;43:2258-2269.

6. Clynes MP, Raftery SE. Feedback: an essential element of student learning in clinical practice. Nurse Educ Pract. 2008;8(6):405-11. 7. Kogan JR, Conforti LN, Bernabeo EC, Durning SJ, Hauer KE, Holmboe ES. Faculty staff perceptions of feedback to residents after direct observation of clinical skills. Med Educ. 2012;46:201-215.

8. Bengtsson M, Carlson E. Knowledge and skills needed to improve as preceptor: development of continuous professional development course - a qualitative study part I. BMC Nurs. 2015;16(14):51.

9. Wilkinson ST, Couldry R, Phillips H, Buck B. Preceptor development: providing effective feedback. Hosp Pharm. 2013;48(1):26-32.

10. Holmes DS. Effects of grades and disconfirmed grade expectancies on students' evaluations of their instructor. $J$ Educ Psychol. 1972;63:130-133.

11. Powell RW. Grades, learning, and student evaluation of instruction. Res High Educ. 1977;7:193-205.

12. Vasta R, Sarmiento RF. Liberal grading improves evaluations but not performance. J Educ Psychol. 1979;71:207-211.

13. Worthington AG, Wong PTP. Effects of earned and assigned grades on student evaluations of an instructor. J Educ Psychol. 1979;71(6):764-775.

14. Kidd RS, Latif DA. Student evaluations: are they valid measures of course effectiveness. Am J Pharm Educ. 2004;68(3):Article 61. 15. Assemi M, Corelli RL, Ambrose PJ. Development needs of volunteer pharmacy practice preceptors. Am J Phar Educ. 2011;75(1): 10 .

16. Crowne DP, Marlowe D. A new scale of social desirability independent of psychopathology. Journal of Consulting Psychology. 1960;24(4):349-354.

17. Paulhus DL. Measurement and control of response bias. In: Robinson JP, Shaver PR, Wrightsman LS, eds. Measures of Personality and Social Psychological Attitudes. San Diego, CA: Academic Press. 1991:17-59.

18. Stöber J. The Social Desirability Scale-17 (SDS-17): convergent validity, discriminant validity, and relationship with age. European Journal of Psychological Assessment. 2001;17(3):222-232. 